\title{
Identification of a novel foot-and-mouth disease virus specific T-cell epitope with immunodominant characteristics in cattle with MHC serotype A31
}

\author{
Wilhelm GERNER ${ }^{\mathrm{a}, \mathrm{b}, \mathrm{c} *}$, B. Veronica CARR ${ }^{\mathrm{d}}$, Karl-Heinz WIESMÜLLER $^{\mathrm{e}}$, \\ Eberhard PFAFF ${ }^{\mathrm{b}}$, Armin SAALMÜLLER $^{\mathrm{b}, \mathrm{c}}$, Bryan CHARLESTON $^{\mathrm{a}, \mathrm{d}}$ \\ ${ }^{a}$ Institute for Animal Health, Pirbright Laboratory, Ash Road, Pirbright, Surrey, GU24 0NF, \\ United Kingdom \\ ${ }^{b}$ Friedrich-Loeffler-Institute, Federal Research Institute for Animal Health, Institute of Immunology, \\ Paul-Ehrlich Str. 28, 72076 Tübingen, Germany \\ ${ }^{c}$ Present address: University of Veterinary Medicine Vienna, Clinical Immunology, Veterinärplatz 1, \\ 1210 Vienna, Austria \\ ${ }^{d}$ Institute for Animal Health, Compton Laboratory, Compton, Newbury, Berks, RG20 7NN, \\ United Kingdom \\ ${ }^{e}$ EMC microcollections GmbH, Sindelfinger Str. 3, 72070 Tübingen, Germany
}

(Received 12 October 2006; accepted 29 January 2007)

\begin{abstract}
To identify foot-and-mouth disease virus (FMDV) specific T-cell epitopes within the entire polyprotein sequence of the virus, 442 overlapping pentadecapeptides were tested in proliferation assays using lymphocytes from cattle experimentally infected with FMDV. Four months post-infection cells from all investigated animals $(n=4)$ responded by proliferation and interferon$\gamma$ production to a peptide located on the structural protein 1D (VP1), amino acid residues 66-80. Major histocompatibility complex (MHC) serotyping of the investigated cattle indicated that all animals shared the MHC serotype A31 which comprises the class II allele DRB3 0701. This may explain the common recognition of this newly discovered epitope. Responses to other peptides could only be observed in one animal and rapidly declined during the time course of the study. These observations point to an immunodominant role of this epitope located on the protein $1 \mathrm{D}$ in cattle with MHC serotype A31.
\end{abstract}

cattle / foot-and-mouth disease virus / T-cell epitope / immunodominance

\section{INTRODUCTION}

Foot-and-mouth disease virus (FMDV) is a member of the family Picornaviridae, genus Aphthovirus. The virus genome consists of a positive stranded RNA molecule of about 8500 nucleotides, which encodes

* Corresponding author:

Wilhelm.Gerner@vu-wien.ac.at four structural proteins $(1 \mathrm{~A}, 1 \mathrm{~B}, 1 \mathrm{C}, 1 \mathrm{D})$ and nine non-structural proteins (L/L', 2A, 2B, 2C, 3A, 3B, 3C, 3D) [14]. FMDV causes an extremely contagious disease with high morbidity in cloven-hoofed animals, including important livestock species such as cattle and swine. Although this epizootic can be controlled by the use of a chemically inactivated whole virus 
vaccine, member states of the European Union and a number of other countries have abandoned vaccination due to several disadvantages of this vaccine [11]. This leaves livestock herds in these countries prone to sudden outbreaks of FMD and in turn has led to intensive research for alternative vaccination strategies.

For the design of novel vaccines, a detailed knowledge of antigenic regions recognised not only by B-cells but also by T-cells of the respective host is crucial. However, the identification of T-cell epitopes is impaired by the fact that FMDV shows a high degree of sequence variation in its capsid proteins, illustrated by the existence of seven different serotypes with a large number of subtypes $[3,10]$. Despite this heterogeneity, a number of T-cell epitopes have been identified within the structural proteins by the use of overlapping peptides in in-vitro re-stimulation assays in cattle $[4,5,15,17]$. Some of these described epitopes were also investigated in experiments with MHC typed animals [9, 15-17]. The use of recombinant FMDV proteins in re-stimulation assays identified the nonstructural protein $3 \mathrm{D}$ as an immunodominant T-cell antigen [6]. However, to our knowledge no study was undertaken so far where the complete FMDV polyprotein sequence has been tested for the presence of T-cell epitopes. Therefore, the aim of our investigation was to identify such epitopes within the entire FMDV protein sequence by using overlapping pentadecapeptides and lymphocytes of cattle which had been previously infected with FMDV.

\section{MATERIALS AND METHODS}

\subsection{Animals}

Four FMDV naïve male Holstein cattle (C5, C9, C10, C13) were infected at six months of age by intradermal tongue inoculation with the FMDV strain causing the $2001 \mathrm{UK}$ epidemic, classified as
$\mathrm{O} / \mathrm{UKG} / 35 / 2001$ [12]. Infection was confirmed by the detection of virus in blood and probang samples as well as seroconversion. One of the animals (C9) was diagnosed as an FMDV carrier and killed 16 weeks post infection (p.i.) to allow movement of the animals to a long-term holding facility. The animals were derived from a herd under a controlled breeding scheme where selection according to MHC haplotypes is applied. Therefore, a serological MHC typing had been performed. The animals in this study were all derived by embryo transfer from a single mating of an A31/A20 dam with an A31/A31 sire. The offspring animals C5, C9 and C10 were heterozygous with haplotypes A31/A20, whereas animal C13 was homozygous for the A31 haplotype. Therefore, all animals shared the serological specificity A31, which identifies Bovine Leukocyte Antigen (BoLA) class I alleles $\mathrm{N}^{*} 02101$ and $\mathrm{N}^{*} 02201$ [8] and BoLA class II allele DRB3*0701 [7].

\subsection{Peptides}

The peptides used in this study were based on the sequence of FMDV strain $\mathrm{O} / \mathrm{UKG} / 35 / 2001$ which was used to infect the animals under investigation. Each peptide was 15 amino acid (aa) residues long and overlapped by 10 aa-residues, starting from the N-terminal ends of the proteins. This led to a total of 442 peptides covering the entire FMDV polyprotein sequence. Synthesis and analysis of the synthetic peptides used in this study had been performed as described elsewhere [1].

\subsection{Lymphocyte proliferation assays}

Heparinised blood was collected and peripheral blood mononuclear cells (PBMC) were isolated according to a standard procedure. PBMC were resuspended 
in RPMI1640 with L-glutamine (Gibco, Paisley, UK), supplemented with $10 \%$ fetal calf serum (TCS Cellworks, Buckingham, UK) and plated $\left(2 \times 10^{5}\right.$ cells/well $)$ in 96-well round-bottomed microtitre plates (BD Falcon, Bedford, USA). For the initial screening, each peptide was tested in four wells, but with different peptide concentrations in each well: $20,10,5$ and $2.5 \mu \mathrm{g} / \mathrm{mL}$ respectively. Cells in medium alone and cells incubated with a 15-mer peptide containing the aa residues 81 to 95 from the Core protein of the classical swine fever virus served as negative controls. After five days, cultures were pulsed with $1 \mu \mathrm{Ci}$ of methyl- ${ }^{3} \mathrm{H}$-thymidine for $18 \mathrm{~h}$. The cells were collected and incorporation of ${ }^{3} \mathrm{H}$-thymidine was measured by liquid scintillation counting. Peptides stimulating counts per minute (c.p.m.) at least threefold above the control cultures were considered positive and were reinvestigated in triplicate cultures.

\subsection{Interferon- $\gamma$ ELISPOT assays}

Ninety-six-well nitrocellulose plates (Millipore, Molsheim, France) were coated with anti-bovine Interferon- $\gamma$ $(\mathrm{IFN}-\gamma)$ monoclonal antibody (mAb, clone CC330) at $8 \mu \mathrm{g} / \mathrm{mL}$ in PBS, using $100 \mu \mathrm{L} /$ well and stored over night at $4{ }^{\circ} \mathrm{C}$. Subsequently, either $5 \times 10^{5}$ or $2 \times 10^{5}$ PBMC per well were incubated for $24 \mathrm{~h}\left(37{ }^{\circ} \mathrm{C}\right.$ and $\left.5 \% \mathrm{CO}_{2}\right)$ in triplicates with $10 \mu \mathrm{g} / \mathrm{mL}$ of positive peptides as identified in ${ }^{3} \mathrm{H}$-thymidine incorporation assays. Plates were washed four times and then incubated for two hours at $37{ }^{\circ} \mathrm{C}$ with a biotinylated anti-bovine IFN- $\gamma$ $\mathrm{mAb}$ (clone CC302) at a concentration of $5 \mu \mathrm{g} / \mathrm{mL}$ in PBS using $100 \mu \mathrm{L} /$ well. This was followed by incubation with streptavidin alkaline phosphatase (Caltag, Burlingame, USA) for $1 \mathrm{~h}$ at room temperature, diluted 1:1000 in PBS and used at $50 \mu \mathrm{L} /$ well. Finally, an alka- line phosphatase substrate kit (Bio-Rad, Hemel Hempstead, UK) was used for visualisation of the spots.

\section{RESULTS}

At approximately four months p.i. the four cattle were investigated for the presence of long-lived FMDV-specific memory T-cells. The initial screening process with 442 peptides covering the complete FMDV protein sequence was performed over a 10-day period and was completed 16 weeks p.i. One peptide designated 252, representing aa residues $66-80$ on the structural protein 1D (VP1), was recognised by PBMC from all four investigated animals in a dose dependent manner. The results of proliferation assays are displayed in Figure 1A, showing the response of PBMC from three animals (C5, C10, C13) 21 weeks p.i. For animal C9 the response 16 weeks p.i. is shown, since this animal had to be slaughtered early within the experimental phase. Also, the production of IFN- $\gamma$ was examined in ELISPOT assays after stimulation with peptide 252 for animals $\mathrm{C} 5, \mathrm{C} 10$ and $\mathrm{C} 13$ using two different cell concentrations, $5 \times 10^{5}$ or $2 \times 10^{5} \mathrm{PBMC} /$ well, respectively (Fig. 1B, response 20 weeks p.i.). There was a correlation between the responses to this peptide in both assay types for each individual animal, with $\mathrm{C} 10$ apparently being a low responder, $\mathrm{C} 5$ showing an intermediate response and PBMC from $\mathrm{C} 13$ showing the highest response. This high response of animal C13 coincides with the homozygosity for the A31 haplotype. Peptide 252 was also tested with PBMC of two FMDV naïve cattle by proliferation and IFN- $\gamma$ ELISPOT assays. In these experiments, no response was observed (data not shown); therefore ruling out a general immunostimulating property of this peptide.

Further reactive peptides could be identified for animal $\mathrm{C} 13$ by ${ }^{3} \mathrm{H}$-thymidine 


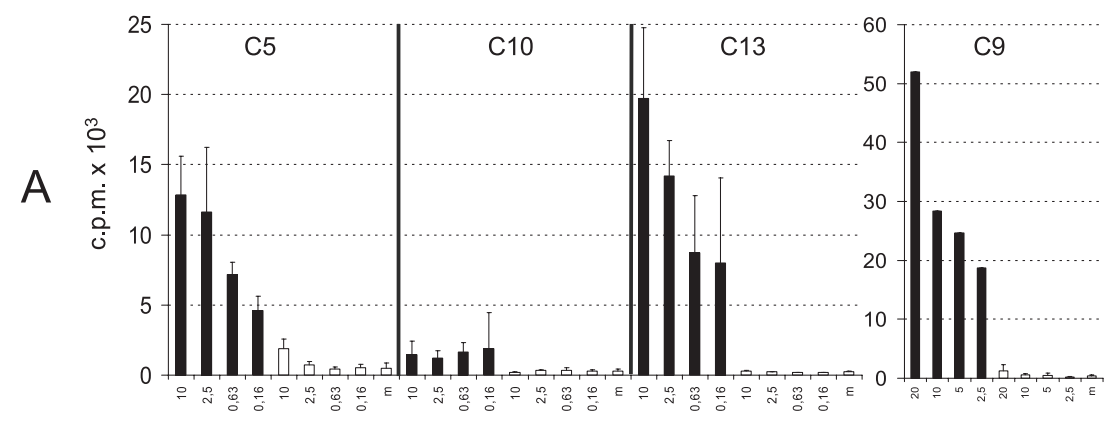

$\mu \mathrm{g}$ peptide/mL

peptide $252 \square$ control peptide, medium

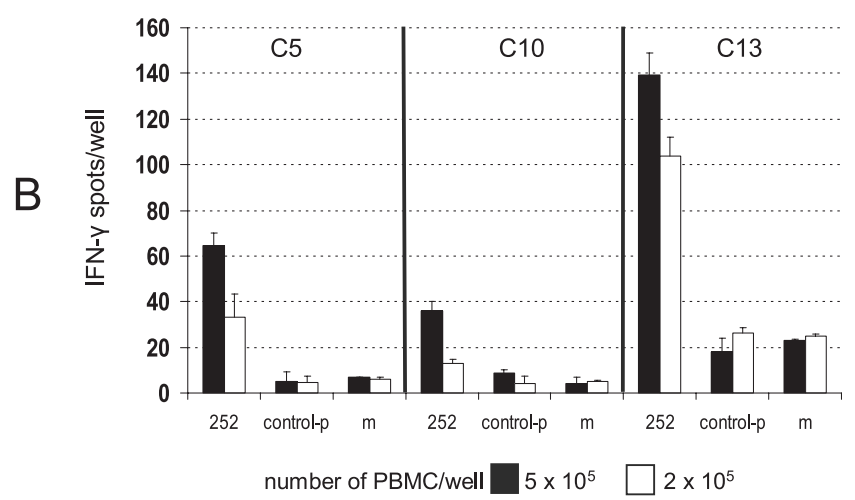

Figure 1. Proliferative and IFN- $\gamma$ response of PBMC from investigated cattle against FMDV derived peptide 252. (A) PBMC from four cattle (C5, C10, C13, C9) were tested for proliferative response against FMDV peptide 252 in ${ }^{3} \mathrm{H}$-thymidine incorporation assays. Black bars show c.p.m. values of different concentrations of peptide $252(10,2.5,0.63$ and $0.16 \mu \mathrm{g} / \mathrm{mL}$ respectively) against the c.p.m. values of a control peptide and medium (white bars, 15-mer peptide from the Core protein of the classical swine fever virus). Results are expressed as c.p.m. mean values + standard deviations of hexaplicate cultures. Animal C9 was removed from the study 16 weeks p.i. and could therefore not be tested in parallel with the other animals. For C9 single values for peptide 252 and triplicate values for control peptide and medium are shown. (B) PBMC of animals C5, C10 and C13 were tested in IFN- $\gamma$ ELISPOT assays after in-vitro peptide stimulation. Two different cell concentrations were used: $5 \times 10^{5}$ (black bars) and $2 \times 10^{5}$ (white bars) PBMC/well. Peptide concentration was $10 \mu \mathrm{g} / \mathrm{mL}$. Results are expressed as mean values + standard deviations of triplicate cultures.

incorporation assays. At 16 weeks p.i. when peptide 252 and its neighbouring peptide 253 were tested for the first time with PBMC from this animal, three further peptides with numbers 109, 128 and 190 induced proliferation (Fig. 2A). One week earlier during the initial screening process, these peptides had already been considered positive and were re-tested 16 weeks p.i. The response to these peptides was lower compared to peptide 252 but still considerably above control cultures. However, testing the same set of peptides five weeks later at 21 weeks p.i. 

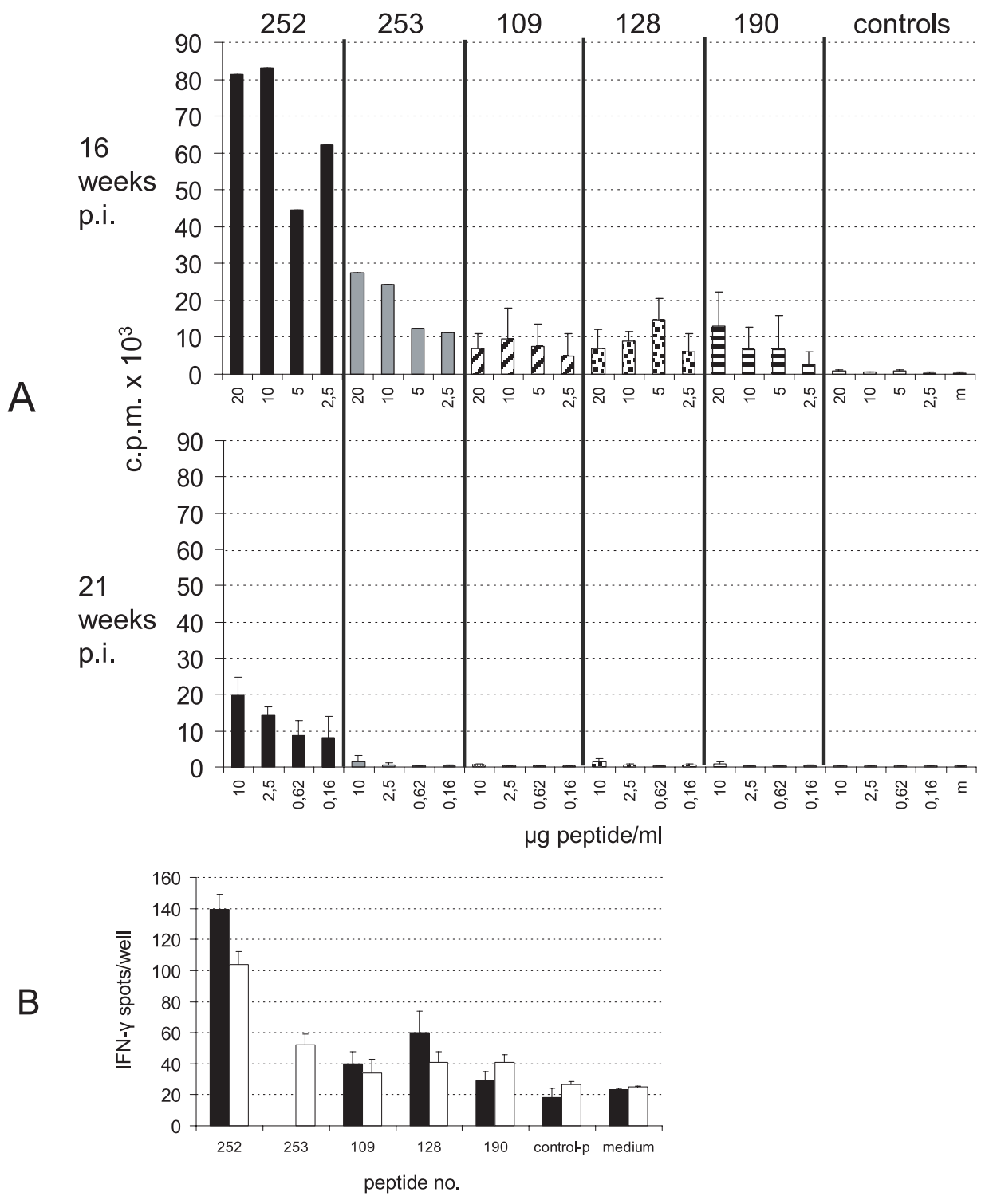

number of PBMC/well $\square 5 \times 10^{5} \quad \square 2 \times 10^{5}$

Figure 2. Proliferative and IFN- $\gamma$ response of PBMC from animal C13 against various FMDV derived peptides. (A) 16 weeks p.i. five reactive peptides could be identified for animal $\mathrm{C} 13$ by ${ }^{3} \mathrm{H}$-thymidine incorporation assays. For peptides 252 (black bars) and 253 (grey bars) single c.p.m. values and for peptides 109 (diagonal hatched bars), 128 (black spotted bars) and 190 (horizontal hatched bars) c.p.m. mean values + standard deviations of triplicate cultures are shown, each time for four different peptide concentrations: 20, 10, 5 and $2.5 \mu \mathrm{g} / \mathrm{mL}$ respectively. At 21 weeks p.i., these peptides were re-tested in triplicate cultures by ${ }^{3} \mathrm{H}$-thymidine incorporation assays using different peptide concentrations: 10, 2.5, 0.63 and $0.16 \mu \mathrm{g} / \mathrm{mL}$ respectively. (B) At 20 weeks p.i., the same peptides were tested in IFN- $\gamma$ ELISPOT assays using two different cell concentrations: $5 \times 10^{5}$ (black bars) and $2 \times 10^{5}$ (white bars) PBMC/well. Peptide concentration was $10 \mu \mathrm{g} / \mathrm{mL}$. Results are expressed as mean values + standard deviations of triplicate cultures. 
Table I. Summary of amino acid sequences and positions of peptides in respective FMDV proteins inducing IFN- $\gamma$ response and lymphocyte proliferation in FMDV infected cattle.

\begin{tabular}{lclcc}
\hline FMDV protein & Peptide no & \multicolumn{1}{c}{ Sequence } & Residues & Recognised by $^{\mathrm{a}}$ \\
\hline 1B & 190 & PWTLVVMVVAPLTVN & $176-190$ & C13 \\
1D & 252 & LRTATYYFADLEVAV & $66-80$ & C5, C9, C10, C13 \\
& 253 & YYFADLEVAVKHEGN & $71-85$ & C13 \\
2C & 109 & GNIHIANLCKVVAPA & $81-95$ & C13 \\
& 128 & QMVSTTGFIPPMASL & $176-190$ & C13 \\
C $^{\text {b }}$ & Negative control & KLEKALLAWAVIAIV & $81-95$ & - \\
\hline
\end{tabular}

a Animal number.

${ }^{\mathrm{b}}$ Core protein of the classical swine fever virus.

with PBMC of animal C13 yielded only a response to peptide 252 , while the other peptides failed to induce proliferation. A test of these peptides in an ELISPOT assay at 20 weeks p.i. gave similar results with peptides $253,109,128$ and 190 inducing IFN- $\gamma$ production only slightly above control cultures, whereas peptide 252 had a frequency of IFN- $\gamma$ producing cells at least five-fold higher than the controls (Fig. 2B).

A summary of the sequences and locations within the respective FMDV proteins of peptides stimulating proliferation and IFN- $\gamma$ production is listed in Table I.

\section{DISCUSSION}

Despite the effort of testing 442 peptides covering the complete FMDV protein sequence, in three of four investigated animals, only one reactive peptide (peptide 252) could be identified. One possible explanation for this could be a phenomenon called immunodominance. It describes the observation that naturally occurring immune responses often do not recognise all possible epitopes of a particular antigen, but are instead focussed on relatively few or even a singular epitope (reviewed in [13]). Several reasons are discussed for this phenomenon, including binding properties of peptides in particular MHC molecules, the spectrum of the T-cell repertoire involved in recognition of peptide-MHC complexes, quality of co-stimulation and competition among reactive T-cell clones. Competition between T-cell clones may be occurring in our experimental system, since T-cells from animal $\mathrm{C} 13$ responded to four further peptides, with three of them representing separate epitopes. However, the reactivity of these peptides rapidly declined during the time course of the study. Therefore, it may be assumed that early after infection, the other cattle also had a broader spectrum of reactive $\mathrm{T}$-cell clones, but at the time point when our experiments were performed, the frequency of these clones may have been already strongly diminished or they were no longer present in the circulation. Using PBMC from animals that were infected only once, may also have contributed to a rapid decline of memory T-cells in circulation. Nevertheless, the identification of antigenic regions inducing such long-lasting T-cell clones is probably beneficial with regards to vaccine development, because by incorporating such antigenic regions in vaccine formulations a situation occurring during natural infections may be mimicked and could contribute to a protective cellular immune response.

A number of investigators tested peptides derived from structural FMDV 
proteins for reactivity with cells from FMDV infected cattle [4, 5, 15]. No group reported the epitope located on $1 \mathrm{D}$, aa residues 66-80, that we identified. However, in the study where an analysis of BoLA class II DRB alleles had been performed [15], the animals carried different DRB alleles from our cattle. In turn, our study did not identify the MHC promiscuous epitope on protein $1 \mathrm{~A}$ (VP4, aa residues 20-34) which has been described in a number of studies in cattle [15-17] and even swine [2]. However, this might be again attributable to the MHC type of our animals, because in studies where the VP4 epitope has been identified and a class II typing had been performed, the cattle did not express the BoLA DRB3 0701 allele [9, 15-17].

This study adds another piece in our slowly emerging picture of antigenic structures recognised by bovine T-cells in response to infection with FMDV. However, the question of whether epitopes are located in the conserved non-structural proteins of the virus, which is of great interest with regards to vaccine improvement, could not be answered using cattle infected only once. Future experiments should investigate a longer period after invivo priming of animals, thereby broadening our knowledge about immunodominant epitopes which are established in FMDV infections. Also, by investigating the immune response after multiple challenges with different FMDV serotypes, promiscuous dominant epitopes might be identified. This together with information on the haplotypes prevalent in commercial cattle herds could be very helpful for the design of novel vaccines consisting of defined $\mathrm{T}$ and B-cell epitopes.

\section{ACKNOWLEDGEMENTS}

The authors would like to thank Haru-Hisa Takamatsu and Michael S. Denyer for hosting and supporting W. Gerner in their laboratory at the IAH Pirbright for the performance of the invitro experiments. We also would like to thank Zhidong Zhang for bleeding of the animals.

\section{REFERENCES}

[1] Armengol E., Wiesmüller K.H., Wienhold D., Büttner M., Pfaff E., Jung G., Saalmüller A., Identification of T-cell epitopes in the structural and non-structural proteins of classical swine fever virus, J. Gen. Virol. (2002) 83:551-560.

[2] Blanco E., McCullough K., Summerfield A., Fiorini J., Andreu D., Chiva C., Borras E., Barnett P., Sobrino F., Interspecies major histocompatibility complex-restricted Th cell epitope on foot-and-mouth disease virus capsid protein VP4, J. Virol. (2000) 74:4902-4907.

[3] Carrillo C., Tulman E.R., Delhon G., Lu Z., Carreno A., Vagnozzi A., Kutish G.F., Rock D.L., Comparative genomics of footand-mouth disease virus, J. Virol. (2005) 79:6487-6504.

[4] Collen T., Doel T.R., Heterotypic recognition of foot-and-mouth disease virus by cattle lymphocytes, J. Gen. Virol. (1990) 71:309-315.

[5] Collen T., Dimarchi R., Doel T.R., A T cell epitope in VP1 of foot-and-mouth disease virus is immunodominant for vaccinated cattle, J. Immunol. (1991) 146:749-755.

[6] Collen T., Baron J., Childerstone A., Corteyn A., Doel T.R., Flint M., Garcia-Valcarcel M., Parkhouse R.M.E., Ryan M.D., Heterotypic recognition of recombinant FMDV proteins by bovine T-cells: the polymerase (P3Dpol) as an immunodominant T-cell immunogen, Virus Res. (1998) 56:125-133.

[7] Collen T., Carr V., Parsons K., Charleston B., Morrison W.I., Analysis of the repertoire of cattle CD4(+) T cells reactive with bovine viral diarrhoea virus, Vet. Immunol. Immunopathol. (2002) 87:235-238.

[8] Ellis S.A., Morrison W.I., MacHugh N.D., Birch J., Burrells A., Stear M.J., Serological and molecular diversity in the cattle MHC class I region, Immunogenetics (2005) 57:601-606.

[9] Haghparast A., Wauben M.H., GrosfeldStulemeyer M.C., van Kooten P., Hensen E.J., Selection of T-cell epitopes from foot-and-mouth disease virus reflects the 
binding affinity to different cattle MHC class II molecules, Immunogenetics (2000) 51:733-742.

[10] Knowles N.J., Samuel A.R., Molecular epidemiology of foot-and-mouth disease virus, Virus Res. (2003) 91:65-80.

[11] Mahy B.W.J., Overview of foot-andmouth disease and its impact as a re-emergent viral infection, in: Sobrino F., Domingo E. (Eds.), Foot and Mouth Disease. Current Perspectives, Horizon Bioscience, Wymondham, Norfolk, UK, 2004, pp. 437-446.

[12] Mason P.W., Pacheco J.M., Zhao Q.Z., Knowles N.J., Comparisons of the complete genomes of Asian, African and European isolates of a recent foot-and-mouth disease virus type $\mathrm{O}$ pandemic strain (PanAsia), J. Gen. Virol. (2003) 84:1583-1593.

[13] Sette A., Fikes J., Epitope-based vaccines: an update on epitope identification, vaccine design and delivery, Curr. Opin. Immunol. (2003) 15:461-470.
[14] Sobrino F., Saiz M., Jimenez-Clavero M.A., Nunez J.I., Rosas M.F., Baranowski E., Ley V., Foot-and-mouth disease virus: a long known virus, but a current threat, Vet. Res. (2001) 32:1-30.

[15] Van Lierop M.J., van Noort J.M., Wagenaar J.P., Rutten V.P., Langeveld J., Meloen R.H., Hensen E.J., T cell-stimulatory fragments of foot-and-mouth disease virus released by mild treatment with cathepsin D, J. Gen. Virol. (1994) 75:2937-2946.

[16] Van Lierop M.J., Nilsson P.R., Wagenaar J.P., van Noort J.M., Campbell J.D., Glass E.J., Joosten I., Hensen E.J., The influence of MHC polymorphism on the selection of T-cell determinants of FMDV in cattle, Immunology (1995) 84:79-85.

[17] Van Lierop M.J., Wagenaar J.P., van Noort J.M., Hensen E.J., Sequences derived from the highly antigenic VP1 region 140 to 160 of foot-and-mouth disease virus do not prime for a bovine $\mathrm{T}$-cell response against intact virus, J. Virol. (1995) 69:4511-4514. 